\title{
A Non-Precious Metal Promoting the Synthesis of 5-Hydroxymethylfurfural
}

\author{
Xinyuan Lu ${ }^{1}$, Hongjie Zhao ${ }^{1}$, Wei Feng ${ }^{2, *}$ and Peijun Ji ${ }^{1, *}$ \\ 1 Department of Chemical Engineering, Beijing University of Chemical Technology, Beijing 100029, China; \\ Xinyuanlu209@outlook.com (X.L.); Hongjiezhao420@163.com (H.Z.) \\ 2 Department of Biochemical Engineering, Beijing University of Chemical Technology, Beijing 100029, China \\ * Correspondence: fengwei@mail.buct.edu.cn (W.F.); jipj@mail.buct.edu.cn (P.J.); \\ Tel.: +86-010-64446249 (W.F.); +86-010-64423254 (P.J.)
}

Received: 26 October 2017; Accepted: 2 November 2017; Published: 6 November 2017

\begin{abstract}
In this work, a new kind of catalyst was prepared for synthesis of 5-hydroxymethylfurfural. Copper ions were incorporated into manganese oxide octahedral molecular sieves (K-OMS-2). The catalysts $\mathrm{Cu}-\mathrm{K}-\mathrm{OMS}-2$ were characterized by measuring FTIR spectra, scanning electron microscope images, X-ray diffraction patterns, and temperature-programmed desorption (TPD) and temperature-programmed reduction (TPR) profiles. Thermogravimetric analysis (TGA) demonstrated that the stability of $\mathrm{Cu}-\mathrm{K}-\mathrm{OMS}-2$ is almost the same as that of K-OMS-2. XRD patterns showed that introducing copper ions did not change the structure of K-OMS-2, but copper ions had an effect on the morphology of K-OMS-2 as illustrated by SEM images. TPD profiles demonstrated that both K-OMS-2 and Cu-K-OMS-2 possess basic and acidic sites, and $\mathrm{Cu}-\mathrm{K}-\mathrm{OMS}-2$ has weak acidic sites. One-pot synthesis of 2,5-diformylfuran (DFF) from fructose was investigated under the catalysis of Cu-K-OMS-2 together with a commercial catalyst Amberlyst 15. The effect of reaction time and temperature on the DFF yield was investigated, and reaction temperature had an effect on the DFF yield. The effect of atomic ratio of $\mathrm{Cu}$ to $\mathrm{Mn}$ of $\mathrm{Cu}-\mathrm{K}-\mathrm{OMS}-2$ on the DFF yield was also investigated. The DFF yield was improved $34.7 \%$ by $\mathrm{Cu}-\mathrm{K}-\mathrm{OMS}-2$ in comparison to K-OMS-2, indicating the promotion effect of copper on the DFF yield. Consecutive use of Cu-K-OMS-2 demonstrated that after 6 cycles, the loss of DFF yield was 6.3\%, indicating a good reusability of Cu-K-OMS-2.
\end{abstract}

Keywords: 2,5-diformylfuran; OMS-2; copper; synthesis

\section{Introduction}

2,5-Diformylfuran (DFF) is a value added chemical with broad application prospects. It can be used either as a monomer, or as a starting material for the synthesis of ligands, drugs, and antifungal agents [1]. DFF can be produced by the oxidation of 5-hydroxymethylfurfural (HMF), and HMF can be produced from biomass resource [2]. Considering economy and sustainability, the aerobic oxidation approach to producing DFF from HMF is preferred [3], by using $\mathrm{O}_{2}$ as oxidant. Developing heterogeneous catalysts has been paid more attention. The goal is to selectively oxidize HMF to DFF. Ruthenium nanoparticles were embedded in mesoporous poly-melamine-formaldehyde, and the conjugate was used for selective oxidation HMF to DFF in solvent toluene [1]. By exchanging $\mathrm{Ru}^{3+}$ with $\mathrm{H}^{+}$in zirconium phosphate, a ruthenium catalyst was prepared and used for the oxidation of HMF. DFF and 2,5-furandicarboxylic acid (FDCA) were the main components of products [4]. Precious metals present advantages over non-precious metals in preparing heterogeneous catalysts. However, precious catalysts are much expensive. Hence non-precious metals have been investigated for catalyst preparation. Mesoporous manganese doped with cobalt oxide was used for the oxidation of HMF to DFF [5]. Vanadium oxide was embedded in zeolites and used for oxidation of HMF to DFF. 
Under the ambient air pressure, the DFF yield of was 83\% [6]. Cellulose-mediated Cu nanoparticles were reported for selective oxidation of HMF to DFF [3].

Transformation of carbohydrates into platform chemicals provides an efficient approach to using a biomass resource. As illustrated in Scheme 1, the process involves two steps including fructose dehydration to HMF and oxidation of HMF to DFF. Few studies have reported the DFF synthesis based on a one-pot approach. Starting from fructose, two catalysts were used sequentially, fructose dehydration using an Amberlyst 15 catalyst and the subsequent oxidation of HMF using an Ru-based catalyst, and the DFF yield was 72.4\% [7]. The Amberlyst 15 catalyst was used together with hydrotalcite-supported Ruthenium catalysts for the synthesis of DFF [8]. Other catalysts, $\mathrm{V}_{2} \mathrm{O}_{5} /$ ceramic powder catalyst with dilute sulfuric acid [9], magnetic $\mathrm{WO}_{3} \mathrm{HO}-\mathrm{VO}-\mathrm{SiO}_{2} @ \mathrm{Fe}_{3} \mathrm{O}_{4}$ with tungstic acid [10], and vanadium oxide [11] have also been reported. High DFF yields are expected from one-pot reaction systems. Developing cost-efficient and environment benign catalytic system for the oxidation of HMF is pursued by researchers.

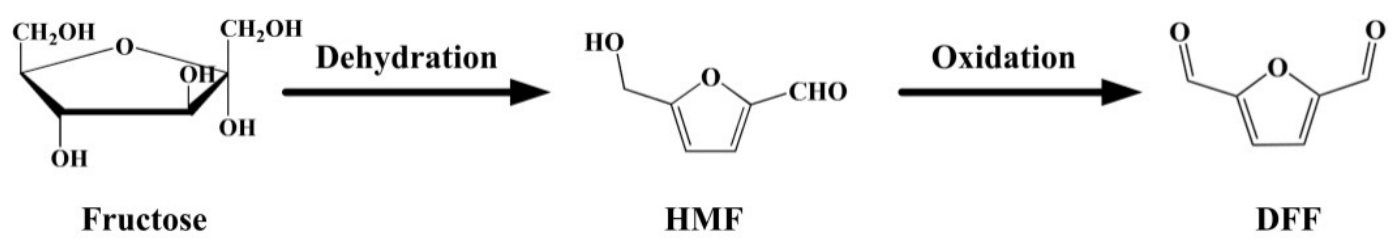

Scheme 1. Transformation of fructose to 2,5-diformylfuran (DFF) via 5-hydroxymethylfurfural (HMF).

Manganese oxide octahedral molecular sieves (K-OMS-2) exhibit unique structural characteristics, including porous structure, mixed valency for $\mathrm{Mn}$ ions (3+ and 4+), and easy release of lattice oxygen. OMS-2 has been explored for preparing catalysts with oxidation functions, and has been used in various systems. The addition of metal ions to K-OMS-2 is a solution to improving its catalytic capability. Transition metal cations and alkali were used to replace $\mathrm{K}^{+}$in the tunnel. The cations have been found to be mobile and can stabilize the structure of the nodule. Some cations can be incorporated into the framework. The cation $\mathrm{K}^{+}$in $\mathrm{K}-\mathrm{OMS}-2$ was substituted with $\mathrm{Ag}^{+}$in the $\mathrm{K}-\mathrm{OMS}-2$, resulting in the formation of Ag-OMS-2, which had been shown as an efficient oxidation catalyst. In this work, copper ions were incorporated into K-OMS-2 for selective oxidation HMF to DFF. One-pot DFF synthesis from fructose under the catalysis of Cu-K-OMS-2 and a commercial catalyst Amberlyst 15 was studied.

\section{Results and Discussion}

\subsection{Characterization of the $\mathrm{Cu}-\mathrm{K}-\mathrm{OMS}-2$ Catalysts}

K-OMS-2 was prepared by adding $\mathrm{KMnO}_{4}$ to the solution of $\mathrm{MnSO}_{4} \cdot \mathrm{H}_{2} \mathrm{O}$ in concentrated $\mathrm{HNO}_{3}$. A serious of Cu-K-OMS-2 were prepared by adding $\mathrm{KMnO}_{4}$ to the solution of $\mathrm{MnSO}_{4} \cdot \mathrm{H}_{2} \mathrm{O}$ and $\mathrm{Cu}\left(\mathrm{NO}_{3}\right)_{2} \cdot 3 \mathrm{H}_{2} \mathrm{O}$ in concentrated $\mathrm{HNO}_{3}$. Cu-K-OMS-2-I, Cu-K-OMS-2-II, and Cu-K-OMS-2-III represent the catalysts prepared with different ratios of $\mathrm{Cu}$ to $\mathrm{Mn}$ in the catalysts as shown in Table 1. The bulk contents of copper and manganese of the samples were determined by ICP-AES.

Table 1. Atomic ratios of $\mathrm{Cu}$ to $\mathrm{Mn}$ in the catalysts.

\begin{tabular}{cc}
\hline Catalysts & Cu/Mn (Atomic Ratio) \\
\hline K-OMS-2 & 0 \\
Cu-K-OMS-2-I & 0.019 \\
Cu-K-OMS-2-II & 0.024 \\
Cu-K-OMS-2-III & 0.031 \\
\hline
\end{tabular}




\subsubsection{Scanning Electron Microscope Images}

Figure 1 shows the scanning electron microscope (SEM) images for K-OMS-2 and Cu-K-OMS-2. Compared to the SEM image of K-OMS-2 (Figure 1a), Cu-K-OMS-2-I exhibited dense microsize particles. Cu-K-OMS-2-II exhibited particles larger than K-OMS-2 and Cu-K-OMS-2-I. K-OMS-2, $\mathrm{Cu}-\mathrm{K}-\mathrm{OMS}-2-\mathrm{I}$, and $\mathrm{Cu}-\mathrm{K}-\mathrm{OMS}-2-\mathrm{III}$ exhibited spherical particles. In contrast, Cu-K-OMS-2-III exhibited shuttle-like particles. Figure 1 shows that the existence of $\mathrm{Cu}$ affected the morphology of the catalysts.

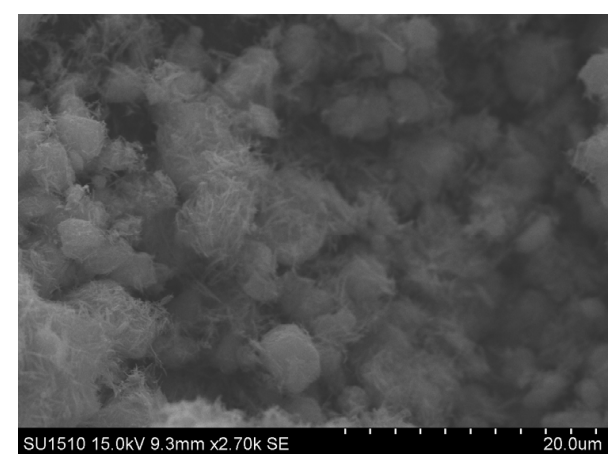

(a)

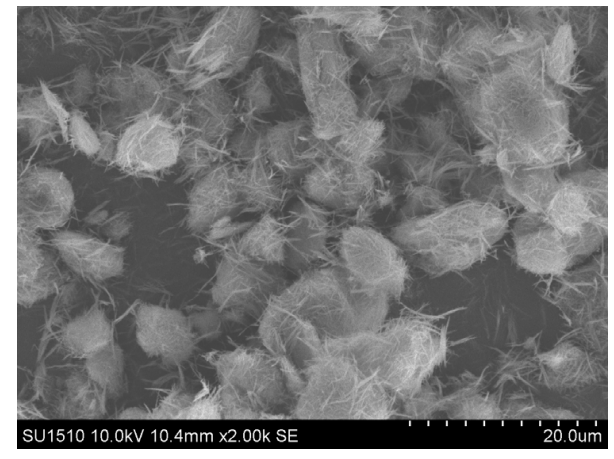

(c)

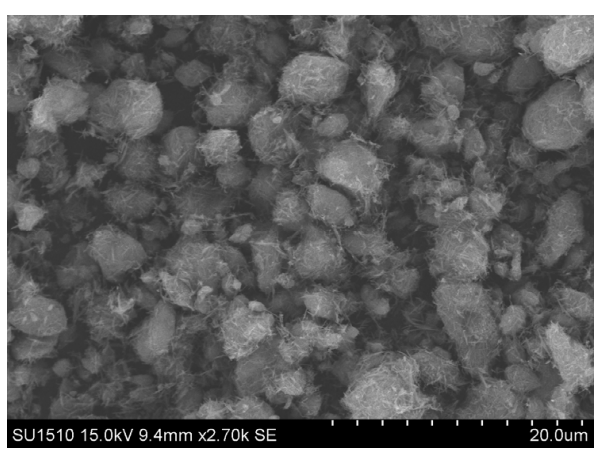

(b)

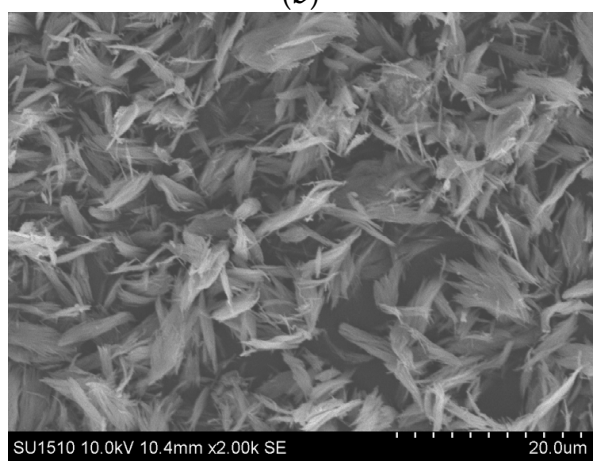

(d)

Figure 1. SEM images. K-OMS-2 (a); Cu-K-OMS-2-I (b); Cu-K-OMS-2-II (c); Cu-K-OMS-2-III (d).

\subsubsection{Spectra of Fourier Transform Infrared Spectoscopy}

K-OMS-2 and Cu-K-OMS-2 were further characterized by Fourier transform infrared spectroscopy (FTIR), as shown in Figure 2. The three bands at 720, 525, and $470 \mathrm{~cm}^{-1}$ were attributed to $\mathrm{Mn}-\mathrm{O}$ and $\mathrm{Cu}-\mathrm{O}$ vibrations $[12,13]$. The FTIR spectra show that the existence of $\mathrm{Cu}$ did not shift the band position. When the ratio of $\mathrm{Cu}$ to $\mathrm{Mn}$ was increased, the band intensity at $470 \mathrm{~cm}^{-1}$ increased. The FTIR spectra confirmed the existence of $\mathrm{Cu}$ in K-OMS-2.

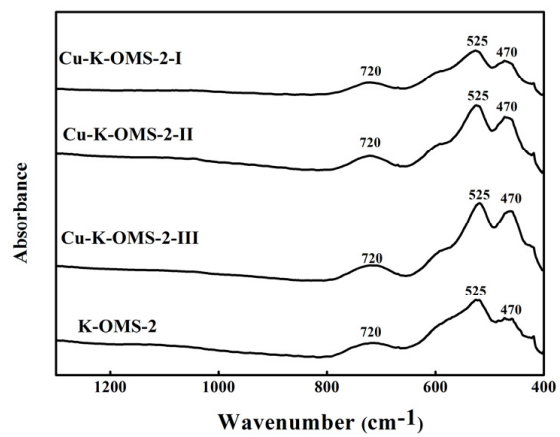

Figure 2. FTIR spectra of K-OMS-2, Cu-K-OMS-2-I, Cu-K-OMS-2-II, and Cu-K-OMS-2-III. 


\subsubsection{X-ray Diffraction (XRD) Patterns}

The X-ray diffraction (XRD) patterns for the catalysts of K-OMS-2, Cu-K-OMS-2-I, Cu-K-OMS-2-II, and $\mathrm{Cu}-\mathrm{K}-\mathrm{OMS}-2-\mathrm{III}$ are shown in Figure 3. The X-ray diffraction patterns of K-OMS-2 catalysts are in good agreement with the standard pattern of pure cryptomelane. The synthesized OMS-2 exhibited typical peaks at $12.74^{\circ}, 18.06^{\circ}, 28.74^{\circ}, 37.62^{\circ}, 42.03^{\circ}, 49.90^{\circ}, 56.18^{\circ}, 60.24^{\circ}$, and $65.52^{\circ}$. These peaks are in consistent with the K-OMS-2 standard card (JCPDS file \#29-1020). All peaks can be indexed to a pure cryptomelane phase (JCPDS 29-1020), and no other phases appeared (Figure 3a). The XRD patterns of $\mathrm{Cu}-\mathrm{K}-\mathrm{OMS}-2-\mathrm{I}, \mathrm{Cu}-\mathrm{K}-\mathrm{OMS}-2-\mathrm{II}$, and Cu-K-OMS-2-III match well with cryptomelane, and no additional phases appeared for the $\mathrm{Cu}$ doped materials (Figure $3 \mathrm{~b}-\mathrm{d}$ ). Thus, $\mathrm{Cu}$ ions were incorporated well in birnessite without causing apparent disorder to the structure of K-OMS-2.
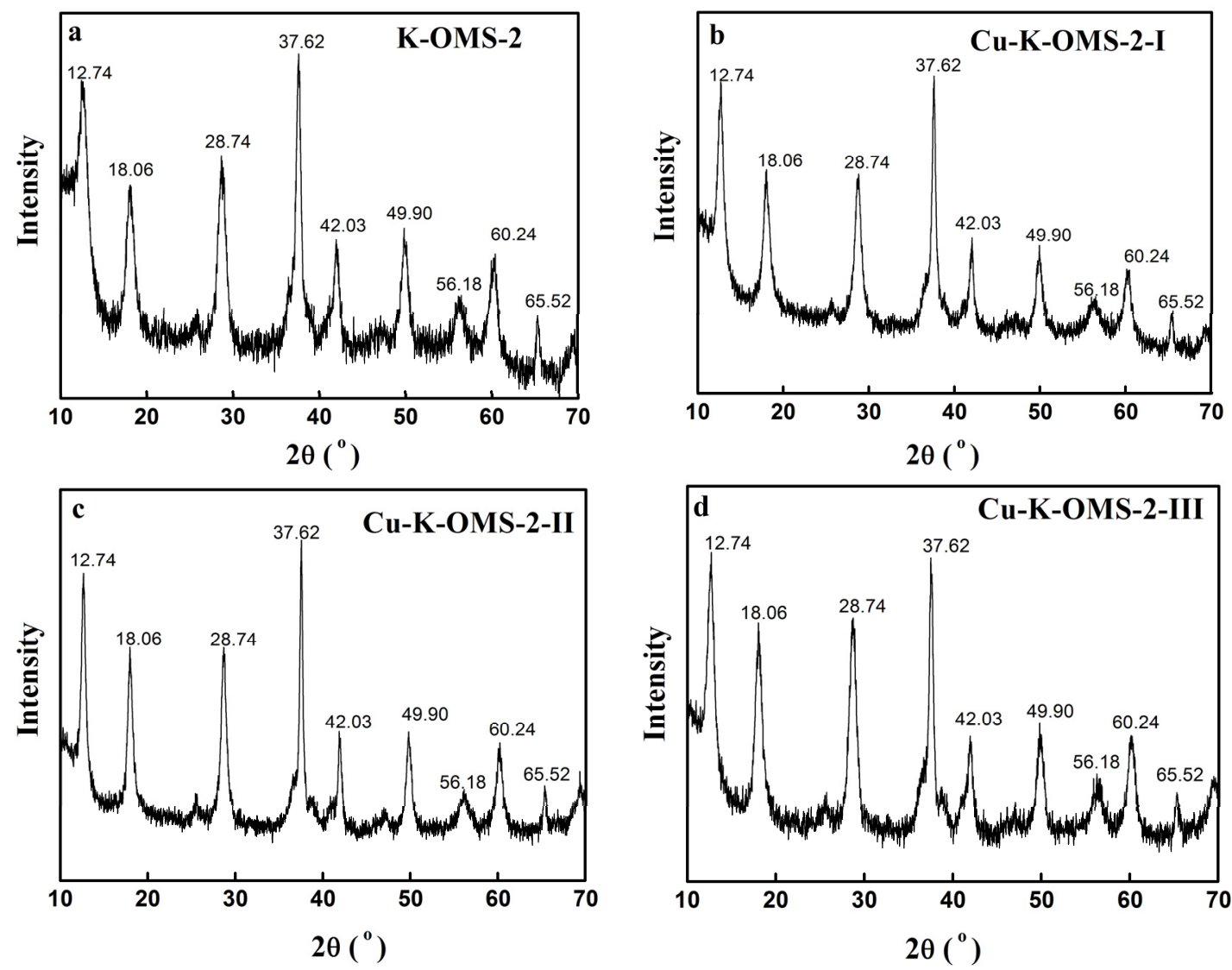

Figure 3. XRD patterns for K-OMS-2 (a), Cu-K-OMS-2-I (b), Cu-K-OMS-2-II (c), and Cu-K-OMS-2-III (d).

\subsubsection{Thermogravimetric Analysis}

The thermal stability of the catalysts was analyzed via thermogravimetric analysis (TGA) measurements as shown in Figure 4. The weight loss versus temperature profiles demonstrate that $\mathrm{Cu}-\mathrm{K}-\mathrm{OMS}-2-\mathrm{II}$ exhibited almost the same stability as that of K-OMS-2. The weight losses were in the following regions: $30-280{ }^{\circ} \mathrm{C}, 280-450{ }^{\circ} \mathrm{C}$, and $570-700{ }^{\circ} \mathrm{C}$. The weight loss from 30 to $280{ }^{\circ} \mathrm{C}$ were attributed to adsorbed water and carbon dioxide. The slight weight loss from 280 to $450{ }^{\circ} \mathrm{C}$ was ascribed to the chemisorbed oxygen. The weight losses in the $570-700^{\circ} \mathrm{C}$ region were ascribed to the collapse of OMS-2 and the decomposition of manganese oxides [14]. 


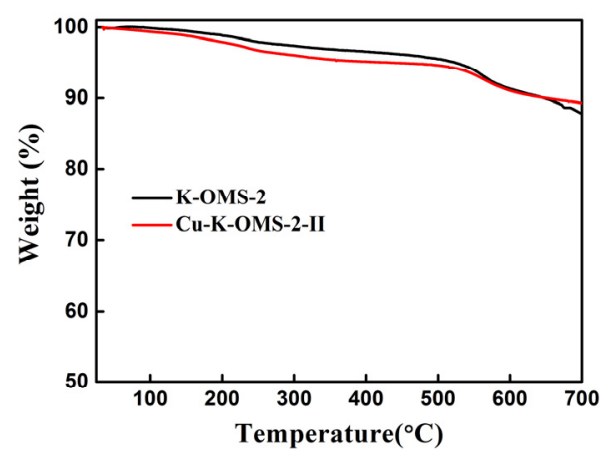

Figure 4. Thermogravimetric analysis (TGA) profiles, weight loss versus temperature, for K-OMS-2 and $\mathrm{Cu}-\mathrm{K}-\mathrm{OMS}-2-\mathrm{II}$.

\subsubsection{Temperature-Programmed Desorption}

Temperature-programmed desorption (TPD) analysis was shown in Figure 5, with carbon dioxide as probe molecule. The profile confirmed that both K-OMS-2 and $\mathrm{Cu}-\mathrm{K}-\mathrm{OMS}-2$ possess basic and acidic sites. The basic sites are provided by $\mathrm{Mn}^{4+}$. Figure 6 shows the TPD analysis with ammonia as probe molecule. Both K-OMS-2 and Cu-K-OMS-2-II have acidic sites on their surfaces, and the desorption peaks at around 220 and $130{ }^{\circ} \mathrm{C}$ were ascribed to the strong and weak acidic sites, respectively. $\mathrm{Cu}-\mathrm{K}-\mathrm{OMS}-2-\mathrm{II}$ has weak acidic sites. Addition of $\mathrm{Cu}$ into K-OMS-2 decreases the acidic sites.

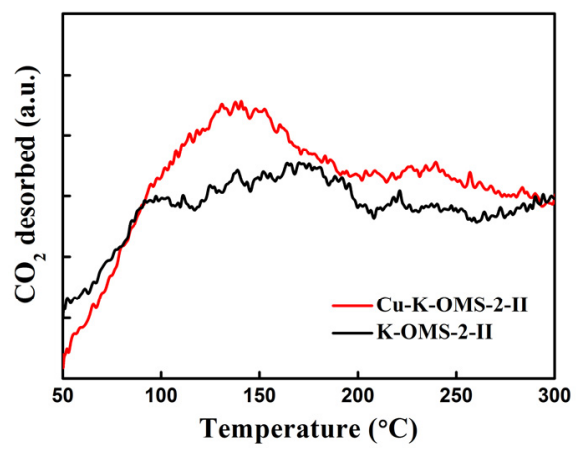

Figure 5. $\mathrm{CO}_{2}-\mathrm{TPD}$ profiles of K-OMS-2 and $\mathrm{Cu}-\mathrm{K}-\mathrm{OMS}-2-\mathrm{II}$. TPD: temperature-programmed desorption.

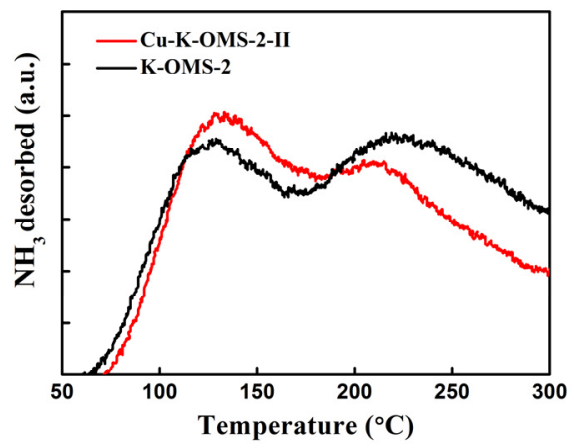

Figure 6. $\mathrm{NH}_{3}$-TPD profiles of K-OMS-2 and $\mathrm{Cu}-\mathrm{K}-\mathrm{OMS}-2-\mathrm{II}$.

\subsubsection{Temperature-Programmed Reduction}

To investigate the stability of the catalyst and effect of oxidation and reduction cycle on the stability, Temperature-programmed reduction (TPR) was carried out twice. Figure 7 shows that there was no major change in the TPR profile of Cu-K-OMS-2-II compared to that of K-OMS-2. The presence 
of copper increases the weak acidity as shown in Figures 5 and 6 for the $\mathrm{CO}_{2}$ and $\mathrm{NH}_{3}$ profiles, respectively. Figure 7 shows that the presence of copper reduced the reduction temperature about $5{ }^{\circ} \mathrm{C}$. Thus, the reduction and oxidation cycle does not change the structure of the catalyst.

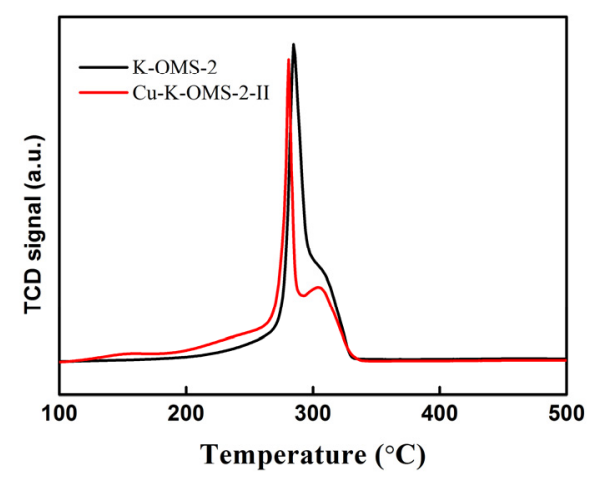

Figure 7. Temperature-programmed reduction (TPR) profiles of K-OMS-2 and Cu-K-OMS-2-II.

\subsection{DFF Synthesis}

Figure 8 shows the HMF yield from the fructose dehydration reaction under the catalysis of Amberlyst 15. Reaction time and temperature affected the HMF yield. Comparison between 30 and 60 min reaction time, the difference in HMF yield is not significant. In contrast, the effect of reaction temperature is more prominent. At $160{ }^{\circ} \mathrm{C}$, about $90 \%$ of $\mathrm{HMF}$ yield were obtained after $30 \mathrm{~min}$. The catalysts $\mathrm{Cu}-\mathrm{K}-\mathrm{OMS}-2$ were used together with a commercial catalyst Amberlyst 15 for one-pot catalysis, converting fructose to DFF.

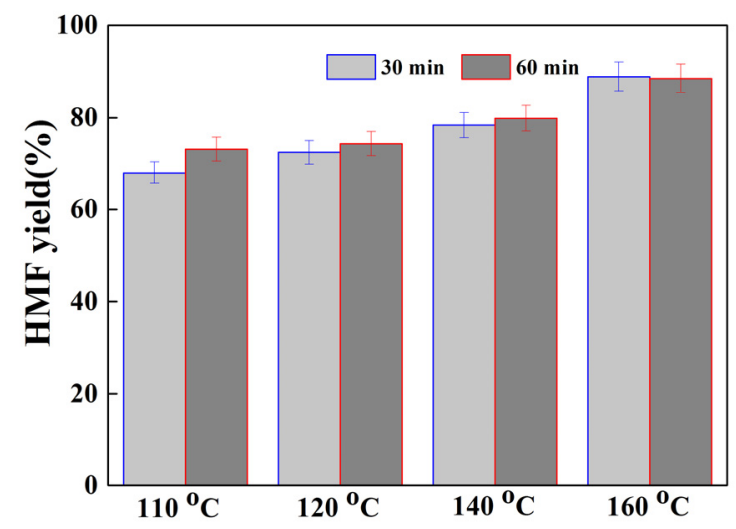

Figure 8. HMF yield as a function of reaction temperature under the catalysis of Amberlyst 15.

Figure 9 illustrates the DFF yield under the catalysis of Amberlyst 15 and different OMS-2 catalysts. The results demonstrated that $\mathrm{Cu}-\mathrm{K}-\mathrm{OMS}-2-\mathrm{II}$ achieved the highest DFF yield, indicating that $\mathrm{Cu}$-K-OMS-2-II has a better catalysis ability than Cu-K-OMS-2-I and Cu-K-OMS-2-III. For further investigations of one-pot catalysis, the catalysis using $\mathrm{Cu}-\mathrm{K}-\mathrm{OMS}-2-\mathrm{II}$ together with Amberlyst 15 was studied. 


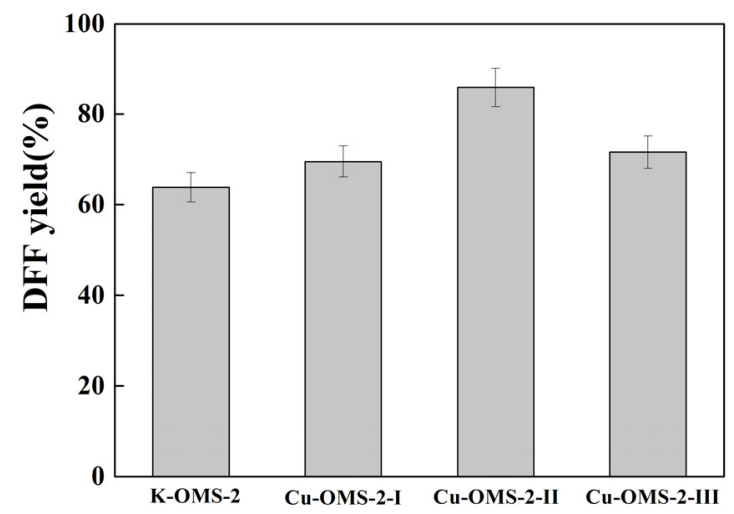

Figure 9. DFF yield under the catalysis of Amberlyst 15 and Cu-K-OMS-2. Reaction time and temperature were $12 \mathrm{~h}$ and $160^{\circ} \mathrm{C}$, respectively.

Figure 10 shows the effect of reaction temperature on the DFF yield. With increasing reaction temperature, the DFF yield increased and the HMF yield decreased. The results in Figure 10 demonstrate that the reaction is intrinsically kinetically controlled. Figure 11 shows the profiles of DFF and HMF yields versus reaction time under the catalysis of Amberlyst 15 and Cu-K-OMS-2-II. The reaction temperature was $160^{\circ} \mathrm{C}$. Due to the continuous conversion of HMF to DFF, the DFF yield increased with reaction time, while the HMF yield decreased with the reaction time. After $12 \mathrm{~h}$, the DFF yield reached the highest values.
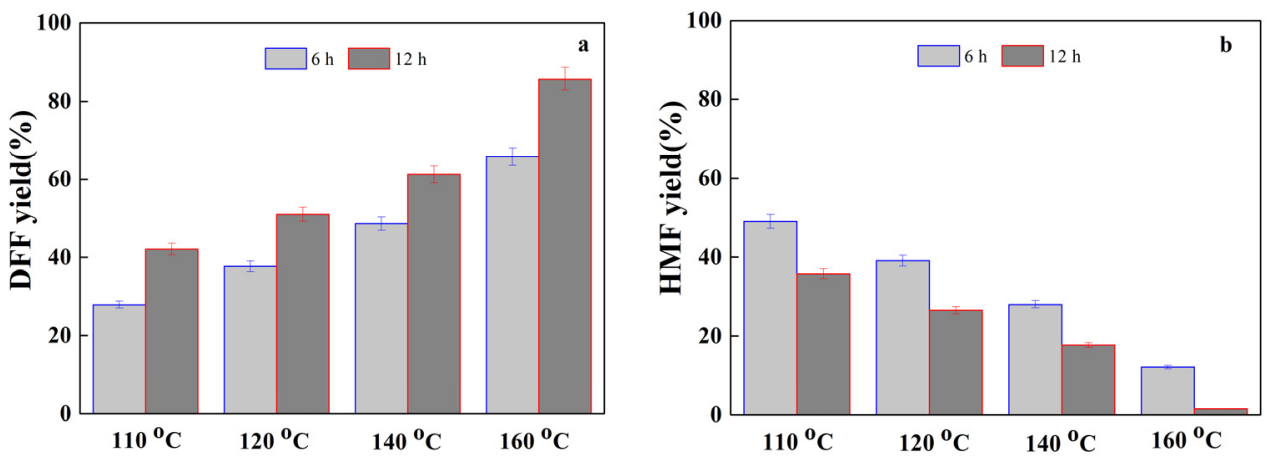

Figure 10. DFF yield (a) and HMF yield (b) as a function of reaction temperature under the catalysis of Amberlyst 15 and Cu-K-OMS-2-II.

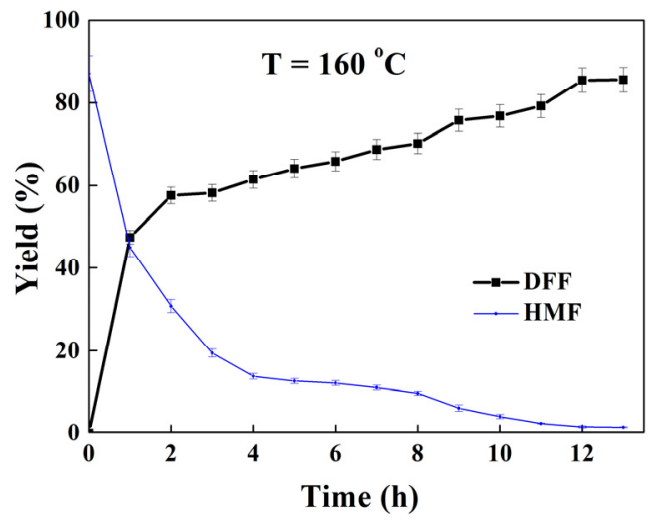

Figure 11. DFF and HMF yields versus reaction time under the catalysis of Amberlyst 15 and $\mathrm{Cu}-\mathrm{K}-\mathrm{OMS}-2-\mathrm{II}$. 
Figure 12 shows the consecutive use of Cu-K-OMS-2-II together with Amberlyst 15 for the conversion of fructose to DFF. After 6 cycles of reuse of the catalysts, the loss of DFF yield was $6.3 \%$, indicating a good reusability of $\mathrm{Cu}-\mathrm{K}-\mathrm{OMS}-2-\mathrm{II}$. The catalysis results demonstrated that incorporating copper ions into K-OMS-2 leading to improved catalysis capability for synthesizing DFF. This is due to a significant enhancement of the lattice oxygen activity in K-OMS-2 arising from the $\mathrm{Cu}$ ion-substituted K-OMS-2 structure with Mn vacancies. In addition, the presence of $\mathrm{Cu}^{2+}$ ions decreases the $\mathrm{Mn}^{2+} / \mathrm{Mn}^{4+}$ ratio in Cu-K-OMS-2 and increases the average oxidation state of Mn [14].

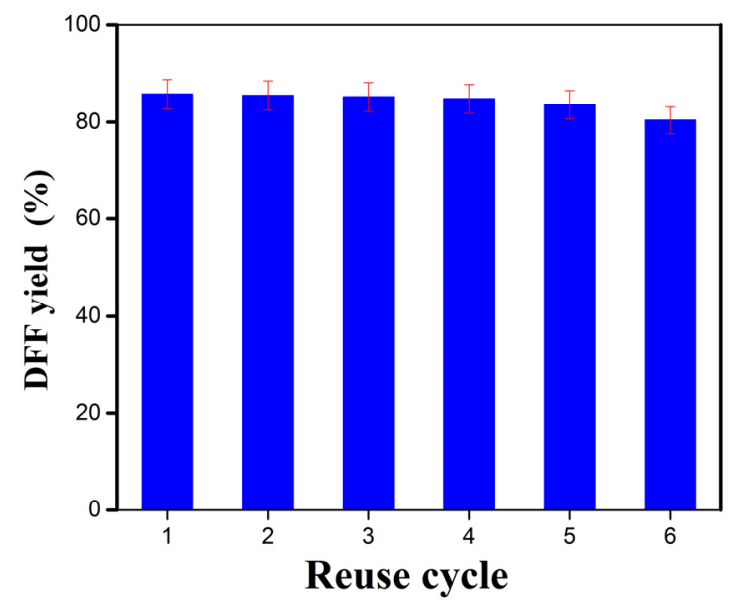

Figure 12. Consecutive use of Cu-K-OMS-2-II for synthesis of DFF.

\section{Experimental Section}

\subsection{Materials}

The chemicals required for the synthesis of catalyst and catalytic reactions were purchased from Sigma-Aldrich (Shanghai, China) or Sinopharm Chemical Reagent Co., Ltd (Shanghai, China) and used as received without further purification.

\subsection{Catalyst Synthesis}

Preparation of K-OMS-2. K-OMS-2 was synthesized by the reflux method [15-18]. The $\mathrm{KMnO}_{4}$ solution $(44.3 \mathrm{mg} / \mathrm{mL})$ was added to a mixture of $\mathrm{MnSO}_{4} \cdot \mathrm{H}_{2} \mathrm{O}$ solution $(66 \mathrm{mg} / \mathrm{mL})$ and concentrated $\mathrm{HNO}_{3}(1.36 \mathrm{~mL})$. The suspension was stirred vigorously and refluxed at $100^{\circ} \mathrm{C}$ for $20 \mathrm{~h}$. After filtration, the precipitate was washed with distilled water until neutral $\mathrm{pH}$ and dried at $120^{\circ} \mathrm{C}$ for $6 \mathrm{~h}$.

Preparation of $\mathrm{Cu}-\mathrm{K}-\mathrm{OMS}-2 . \mathrm{KMnO}_{4}$ solution $(44.3 \mathrm{mg} / \mathrm{mL})$ was added to a mixture of $\mathrm{MnSO}_{4} \cdot \mathrm{H}_{2} \mathrm{O}$ solution $(66 \mathrm{mg} / \mathrm{mL}), \mathrm{Cu}\left(\mathrm{NO}_{3}\right)_{2} \cdot 3 \mathrm{H}_{2} \mathrm{O}(11.8,23.6$ or $35.4 \mathrm{mg} / \mathrm{mL})$, and concentrated $\mathrm{HNO}_{3}(1.36 \mathrm{~mL})$. The suspension was stirred vigorously and refluxed at $100{ }^{\circ} \mathrm{C}$ for $20 \mathrm{~h}$. After filtration, the precipitate was washed with distilled water until neutral $\mathrm{pH}$ and dried at $120^{\circ} \mathrm{C}$ for $6 \mathrm{~h}$.

\subsection{Aerobic Oxidation of HMF}

An amount of $0.36 \mathrm{~g}$ of fructose was dissolved in $10 \mathrm{~mL}$ of DMSO. Then, Amberlyst-15 $(0.2 \mathrm{~g})$ and $\mathrm{Cu}-\mathrm{K}-\mathrm{OMS}-2(0.4 \mathrm{~g})$ were added to the solution. The mixture was heated under stirring. The mixture was mechanically stirred for $30 \mathrm{~min}$, and oxygen was then introduced into the system from the bottom at a flow rate of $20 \mathrm{~mL} \cdot \mathrm{min}^{-1}$. The reaction was carried out for $13 \mathrm{~h}$. After reaction, the catalyst was collected, washed, and dried under vacuum $\left(45^{\circ} \mathrm{C}\right)$ for the next recycling reaction.

HMF, DFF, and intermediates were monitored using HPLC (Shimadzu 15 LC-10A, Shanghai, China) with a Zorbax Eclipse XDB-C8 column (Agilent, Beijing, China) as in our previous work [19]. The mobile phase consisting of phosphate buffer $(12 \mathrm{mM}, \mathrm{pH} 7.0)$ and acetonitrile was flowed into the system at a flow rate of $1.4 \mathrm{~mL} \cdot \mathrm{min}^{-1}$. After $1.6 \mathrm{~min}$ of phosphate buffer flowing, the flow rate 
of acetonitrile was increased to $5 \%$ in $5.0 \mathrm{~min}$ and subsequently to $40 \%$ in $3 \mathrm{~min}$. After $0.5 \mathrm{~min}$ of acetonitrile flowing, phosphate buffer was used as the eluent and maintaining the state for $2 \mathrm{~min}$. Detection was carried out at $268 \mathrm{~nm}$.

\subsection{Characterization}

Infrared spectra were recorded on a Bruker Tensor 27 FTIR spectrometer (BRUKER, Beijing, China) at a resolution of $2 \mathrm{~cm}^{-1}$. The XRD patterns were obtained with a powder diffractometer of $X^{\prime}$ Pert PRO MPD (EPCO, Shanghai, China). The powder diffractograms were scanned at a rate of $1^{\circ} / \mathrm{min}$ from $5^{\circ}$ to $90^{\circ}$. The morphology of Cu-K-OMS-2 and K-OMS-2 was observed by scanning electron microscope (SEM) (TESCAN, Shanghai, China) images. Cu cation loaded in K-OMS-2 was analyzed with inductively coupled plasma-atomic emission spectroscopy (ICP-AES) (Thermo Fisher Scientific, Beijing, China). Thermogravimetric analyses (TGA) (Innuo, Shanghai, China) were carried out with a High TGA 2950 Thermalgravimetric Analyzer with a $60 \mathrm{~mL} / \mathrm{min} \mathrm{N}_{2}$. The temperature was from 25 to $700{ }^{\circ} \mathrm{C}$ at a heating rate of $20^{\circ} \mathrm{C} / \mathrm{min}[20]$.

\section{Conclusions}

Copper ions were incorporated into K-OMS-2. The catalysts Cu-K-OMS-2 exhibited almost the same stability as that of K-OMS-2. Introducing copper ions did not change the structure of K-OMS-2, but copper ions had an effect on the morphology of K-OMS-2. Both K-OMS-2 and Cu-K-OMS-2 possess basic and acidic sites, and Cu-K-OMS-2 has weak acidic sites. One-pot synthesis of 2,5-diformylfuran (DFF) from fructose was investigated under the catalysis of $\mathrm{Cu}-\mathrm{K}-\mathrm{OMS}-2$ together with a commercial catalyst Amberlyst 15. Reaction temperature had an effect on the DFF yield. The atomic ratio of $\mathrm{Cu}$ to Mn of Cu-K-OMS-2 also affects the DFF yield. The DFF yield has been improved $34.7 \%$ by $\mathrm{Cu}-\mathrm{K}-\mathrm{OMS}-2$ in comparison to K-OMS-2, indicating the promotion effect of copper on the DFF yield. Consecutive use of Cu-K-OMS-2 demonstrated that, after 6 cycles, the loss of DFF yield was 6.3\%, indicating a good reusability of $\mathrm{Cu}-\mathrm{K}-\mathrm{OMS}-2$.

Acknowledgments: This work was supported by the National Science Foundation of China (21476023).

Author Contributions: Peijun Ji and Wei Feng provided the idea for the study; Xinyuan Lu and Hongjie Zhao performed the experiments; Xinyuan Lu and Hongjie Zhao drafted the manuscript; Peijun Ji and Wei Feng revised it.

Conflicts of Interest: The authors declare no conflict of interest.

\section{References}

1. Ghosh, K.; Molla, R.A.; Asif Iqubal, M.; Safikul Islam, S.; Manirul Islam, S. Ruthenium nanoparticles supported on $\mathrm{N}$-containing mesoporous polymer catalyzed aerobic oxidation of biomass-derived 5-hydroxymethylfurfural (HMF) to 2,5-diformylfuran (DFF). Appl. Catal. A 2016, 520, 44-52. [CrossRef]

2. Jérôme, F.; Vigier, K.D.O. catalytic conversion of carbohydrates to furanic derivatives in the presence of choline chloride. Catalysts 2017, 7, 218. [CrossRef]

3. Baruah, D.; Hussain, F.L.; Suri, M.; Saikia, U.P.; Sengupta, P.; Dutta, D.K.; Konwar, D. $\mathrm{Bi}\left(\mathrm{NO}_{3}\right)_{3} \cdot 5 \mathrm{H}_{2} \mathrm{O}$ and cellulose mediated $\mathrm{Cu}-\mathrm{NPs}$ - A highly efficient and novel catalytic system for aerobic oxidation of alcohols to carbonyls and synthesis of DFF from HMF. Catal. Commun. 2016, 77, 9-12. [CrossRef]

4. Wang, F.; Yuan, Z.; Liu, B.; Chen, S.; Zhang, Z. Catalytic oxidation of biomass derived 5-hydroxymethylfurfural (HMF) over RuIII-incorporated zirconium phosphate catalyst. J. Ind. Eng. Chem. 2016, 38, 181-185. [CrossRef]

5. Biswas, S.; Dutta, B.; Mannodi-Kanakkithodi, A.; Clarke, R.; Song, W.; Ramprasad, R.; Suib, S.L. Heterogeneous mesoporous manganese/cobalt oxide catalysts for selective oxidation of 5-hydroxymethylfurfural to 2,5-diformylfuran. Chem. Commun. 2017, 53, 11751-11754. [CrossRef] [PubMed]

6. Grasset, F.L.; Katryniok, B.; Paul, S.; Nardello-Rataj, V.; Pera-Titus, M.; Clacens, J.M.; De Campof, F.; Dumeignil, F. Selective oxidation of 5-hydroxymethylfurfural to 2,5-diformylfuran over intercalated vanadium phosphate oxides. RSC Adv. 2013, 3, 9942-9948. [CrossRef] 
7. Wang, W.; Jiang, L.; Wang, J.; Zhang, Z. Catalytic conversion of fructose and 5-hydroxymethylfurfural into 2,5-diformylfuran over SBA-15 supported ruthenium catalysts. Energy Fuels 2016, 30, 5885-5892. [CrossRef]

8. Takagaki, A.; Takahashi, M.; Nishimura, S.; Ebitani, K. One-pot synthesis of 2,5-diformylfuran from carbohydrate derivatives by sulfonated resin and hydrotalcite-supported ruthenium catalysts. ACS Catal. 2011, 1, 1562-1565. [CrossRef]

9. Cui, M.; Huang, R.; Qi, W.; Su, R.; He, Z. Cascade catalysis via dehydration and oxidation: One-pot synthesis of 2,5-diformylfuran from fructose using acid and $\mathrm{V}_{2} \mathrm{O}_{5}$ /ceramic catalysts. RSC Adv. 2017, 7, 7560-7566. [CrossRef]

10. Mittal, N.; Nisola, G.M.; Malihan, L.B.; Seo, J.G.; Kim, H.; Lee, S.P.; Chung, W.J. One-pot synthesis of 2,5-diformylfuran from fructose using a magnetic bi-functional catalyst. RSC Adv. 2016, 6, 25678-25688. [CrossRef]

11. Halliday, G.A.; Young, R.J.; Grushi, V. One-pot, two-step, practical catalytic synthesis of 2,5-diformylfuran from fructose. Org. Lett. 2003, 5, 2003-2005. [CrossRef] [PubMed]

12. Shyam, P.; Chaturvedi, S.; Karmakar, K.; Bhattacharya, A.; Singh, S.; Kulkarni, S. Structural and magnetic investigations on a wet chemically synthesized nanoscale $\mathrm{S}=1 / 2$ spin chain compound- $\mathrm{CuSe}_{2} \mathrm{O}_{5}$. J. Mater. Chem. C 2016, 4, 611-621. [CrossRef]

13. Rowsell, J.L.C.; Taylor, N.J.; Nazar, L.F. Structure and ion exchange properties of a new cobalt borate with a tunnel structure "templated" by Na+. J. Am. Chem. Soc. 2002, 124, 6522-6523. [CrossRef] [PubMed]

14. Wang, R.; Li, J. Effects of precursor and sulfation on OMS-2 catalyst for oxidation of ethanol and acetaldehyde at low temperatures. Environ. Sci. Technol. 2010, 44, 4282-4287. [CrossRef] [PubMed]

15. Kumara, R.; Sithambarama, S.; Suibabc, S.L. Cyclohexane oxidation catalyzed by manganese oxide octahedral molecular sieves-Effect of acidity of the catalyst. J. Catal. 2009, 262, 304-313. [CrossRef]

16. Iyer, A.; Galindo, H.; Sithambaram, S.; Merker, T.; Schleid, T.; Hasse, H.; Gläser, R. Nanoscale manganese oxide octahedral molecular sieves (OMS-2) as efficient photocatalysts in 2-propanol oxidation. Appl. Catal. A 2010, 375, 295-302. [CrossRef]

17. Schurz, F.; Bauchert, J.M.; Merker, T.; Schleid, T.; Hasse, H.; Gläser, R. Octahedral molecular sieves of the type K-OMS-2 with different particle sizes and morphologies: Impact on the catalytic properties in the aerobic partial oxidation of benzyl alcohol. Appl. Catal. A 2009, 355, 42-49. [CrossRef]

18. Deguzman, R.N.; Shen, Y.; Neth, E.J.; Suib, S.L.; O'Young, C.; Levine, S.; Newsam, J.M. Synthesis and characterization of octahedral molecular sieves (OMS-2) having the hollandite structure. Chem. Mater. 1994, 6, 815-821. [CrossRef]

19. Gong, W.; Zheng, K.; Ji, P. Platinum deposited on cerium coordination polymer for catalytic oxidation of hydroxymethylfurfural producing 2,5-furandicarboxylic acid. RSC Adv. 2017, 7, 34776-34782. [CrossRef]

20. Glover, D.; Schumm, B., Jr.; Kozowa, A. (Eds.) Handbook of Manganese Dioxides Battery Grade; International Battery Materials Association: Paris, France, 1989. 